Research Paper

\title{
Prevalence and prognosis of synchronous distant metastatic tonsil squamous cell carcinomas
}

\author{
Yujiao $\mathrm{Li}^{1,2}$, Chaosu $\mathrm{Hu}^{1,2}{ }^{\bowtie}$ \\ 1. Department of Radiation Oncology, Fudan University Shanghai Cancer Center, Shanghai, China. \\ 2. Department of Oncology, Shanghai Medical College, Shanghai, China. \\ $\triangle$ Corresponding author: Pro. Chaosu Hu, Address: Fudan University Shanghai Cancer Center, 270 Dong An Road, Shanghai 200032, China. Tel.: +86 21 64175590 1400; Fax: \\ +8621 64174774; E-mail: hucsu62@yahoo.com. \\ (C) The author(s). This is an open access article distributed under the terms of the Creative Commons Attribution License (https://creativecommons.org/licenses/by/4.0/). \\ See http://ivyspring.com/terms for full terms and conditions.
}

Received: 2020.07.22; Accepted: 2020.11.19; Published: 2021.01.01

\begin{abstract}
Background: To analyze the prevalence proportions and prognostic factors of synchronous distant metastases in patients with tonsil squamous cell carcinomas (TSCC).

Methods: TSCC patients were extracted from the Surveillance, Epidemiology and End Results (SEER) database between 2010 and 2014. We examined the association between clinical manifestations and distant metastases using Chi-squared tests. Predictors of 5-year survival were assessed using univariate and multivariate analyses.

Results: A total of 6193 patients were analyzed and lung was the most common site of distant metastases. Poorly/undifferentiated differentiation was found to be significantly correlated with lung metastasis $(p=0.033)$ and liver and bone metastases were associated with African American $(p=0.000$ and $p=0.000$, respectively). A higher $T$ classification was associated with higher prevalence of lung, liver, bone and brain metastasis $(p=0.000, p=0.000, p=0.000$ and $p=0.007$, respectively). The same results were found in $N$ classification in lung, liver, and bone metastasis $(p=0.000, p=0.000$, and $p=0.000$, respectively). Worse prognosis was associated with older age, Blacks, lower grade, higher $\mathrm{T}$ and $\mathrm{N}$ classification, no surgery therapy and more metastatic sites.

Conclusion: Lung was the most frequent lesion of synchronous distant metastases and liver and bone metastases were associated with African American. Higher $\mathrm{T}$ and $\mathrm{N}$ classification were independent prognostic parameters for higher prevalence of lung, bone, liver and brain metastasis. Worse prognosis was associated with older age, African Americans, lower grade, higher $\mathrm{T}$ and $\mathrm{N}$ classification, no surgery therapy and more metastatic sites.
\end{abstract}

Key words: synchronous distant metastases; tonsil squamous cell carcinomas; metastatic pattern; prevalence; prognosis

\section{Introduction}

Tonsil squamous cell carcinoma (TSCC) is one of the most common oropharyngeal neoplasm and the incidence rates of TSCC have significantly increased in recent decades [1-3]. Several studies have described the association between the clinicopathological characteristics, including age, tumor size, tumor grade, tumor stages at presentation, and lymph node or distant metastases and clinical outcomes of TSCC. Up-front surgery followed by adjuvant therapy, if appropriate, or radiotherapy alone has been the principal treatment modality for early-stage TSCC and postoperative radiotherapy has been used for close or positive resection margins, T3-4 tumors, and neck node metastases [4].

Metastases are the main cause of human cancer deaths, and its treatment continues to be a major challenge. The identification of factors associated with distant metastases is of paramount relevance for therapeutic planning. Our goals were to analyze the prevalence proportions and prognosis of synchronous distant metastases in patients with TSCC using the Surveillance, Epidemiology, and End Results (SEER) database. 


\section{Materials and Methods}

\section{Cohort population}

We obtained data from the current SEER database, which consists of 18 population-based cancer registries. This database collects and publishes cancer prevalence and survival data covering approximately $28 \%$ of the total population in the United States. SEER*Stat Version 8.3.4 (http://www. seer.cancer.gov/seerstat) from the National Cancer Institute was used to identify eligible patients in this study. Because the SEER database began collecting information on the presence or absence of metastases at the time of diagnosis in 2010, we included patients diagnosed with microscopically confirmed TSCC between 1 January 2010 and 31 December 2014. We selected patients with only one primary malignancy in their lifetime. We excluded patients mainly because of lack of pathology type of tumor, unknown racial information, unstaged tumors or 'blanks' metastatic site. In total, 6193 TSCC patients were eligible for inclusion in the prevalence analyses.

\section{Statistical analysis}

Descriptive statistics were used to examine the baseline characteristics of the patients. The primary study outcomes were overall survival (OS) and cancer-specific survival (CSS). OS was defined as time to the date of death due to any cause or the date of last follow-up. CSS was defined as time from initial treatment to death due to cancer. Kaplan-Meier survival curves were compared using the log-rank test. Hazard analysis was conducted using the Cox proportional hazards model. SPSS software, version 22.0 (SPSS, Chicago, IL, USA) was used for additional data processing. A probability value ( $p$ value) of $<0.05$ was considered statistically significant for all tests.

\section{Results}

\section{Clinical Characteristics of all patients}

Data for a total of 6193 patients, including 5083 males and 1110 females, were investigated. The median age was 59 months (range, 17-99 months). Among the cohort of the patients, $4.4 \%, 40.6 \%$ and $55.0 \%$ tumors were well differentiated (Grade I), moderately differentiated (Grade II) and poorly/undifferentiated differentiated (Grade III), respectively. About $63.8 \%$ of the patients were stage IV (Figure 1).

According to the $7^{\text {th }}$ edition of UICC/AJCC Staging System, 1835 patients (29.6\%) were T1, 2484 patients $(40.1 \%)$ were T2, 1023 patients $(16.5 \%)$ were T3, 566 patients $(9.1 \%)$ were $\mathrm{T} 4 \mathrm{a}$, and 285 patients $(4.6 \%)$ were $\mathrm{T} 4 \mathrm{~b}$. With regard to $\mathrm{N}$ classifications, 1259 patients $(20.3 \%)$ were N0, 1296 patients $(20.9 \%)$ were $\mathrm{N} 1,719$ patients $(11.6 \%)$ were N2a, 2087 patients $(33.7 \%)$ were $\mathrm{N} 2 \mathrm{~b}, 555$ patients $(9.0 \%)$ were $\mathrm{N} 2 \mathrm{c}$, and 277 patients $(4.5 \%)$ were N3. Patients' characteristics are listed in Table 1.
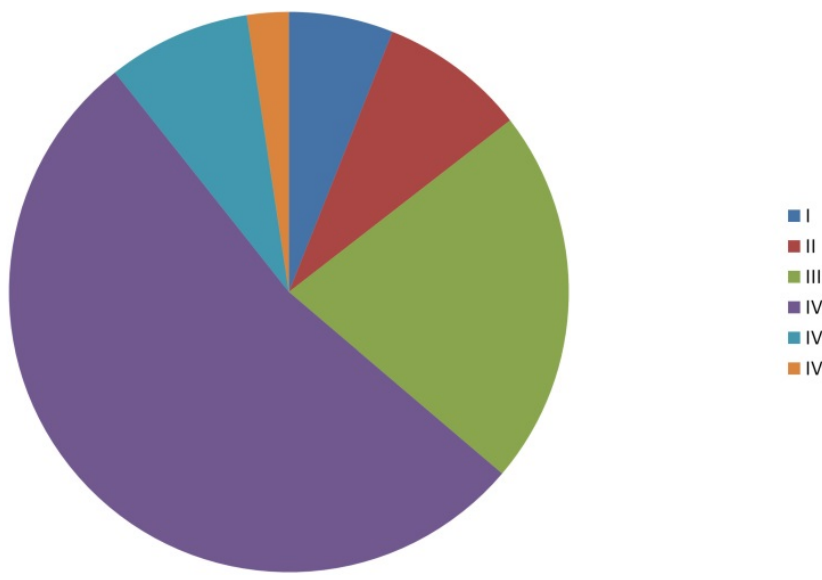

Figure 1. Distribution of tumor stages.

Table 1. Clinical manifestations of 6193 patients

\begin{tabular}{|c|c|c|}
\hline & Number of patients & $\%$ \\
\hline \multicolumn{3}{|l|}{ Age } \\
\hline Median & 59 & \\
\hline Range & $17-99$ & \\
\hline \multicolumn{3}{|l|}{ Gender } \\
\hline Male & 5083 & 82.1 \\
\hline Female & 1110 & 17.9 \\
\hline \multicolumn{3}{|l|}{ Race } \\
\hline Caucasian & 5447 & 88.0 \\
\hline Asian & 221 & 3.6 \\
\hline African American & 525 & 8.5 \\
\hline \multicolumn{3}{|l|}{ T classification } \\
\hline $\mathrm{T} 1$ & 1835 & 29.6 \\
\hline $\mathrm{T} 2$ & 2484 & 40.1 \\
\hline $\mathrm{T} 3$ & 1023 & 16.5 \\
\hline $\mathrm{T} 4 \mathrm{a}$ & 566 & 9.1 \\
\hline $\mathrm{T} 4 \mathrm{~b}$ & 285 & 4.6 \\
\hline \multicolumn{3}{|l|}{$\mathbf{N}$ classification } \\
\hline No & 1259 & 20.3 \\
\hline N1 & 1296 & 20.9 \\
\hline $\mathrm{N} 2 \mathrm{a}$ & 719 & 11.6 \\
\hline $\mathrm{N} 2 \mathrm{~b}$ & 2087 & 33.7 \\
\hline $\mathrm{N} 2 \mathrm{c}$ & 555 & 9.0 \\
\hline N3 & 277 & 4.5 \\
\hline \multicolumn{3}{|l|}{ Grade } \\
\hline 1 & 272 & 4.4 \\
\hline 2 & 2512 & 40.6 \\
\hline 3 & 3409 & 55.0 \\
\hline \multicolumn{3}{|l|}{ Surgery therapy } \\
\hline Yes & 3401 & 54.9 \\
\hline No & 2792 & 45.1 \\
\hline \multicolumn{3}{|l|}{ Tumor location } \\
\hline Tonsillar fossa & 770 & 12.4 \\
\hline Tonsillar pillar & 380 & 6.1 \\
\hline Overlapping lesion of tonsil & 61 & 1.0 \\
\hline Tonsil, NOS & 4982 & 80.4 \\
\hline \multicolumn{3}{|l|}{ Metastasis patterns } \\
\hline No metastasis site & 6091 & 98.4 \\
\hline One metastasis site & 83 & 1.3 \\
\hline Multiple metastasis sites & 3 & 0.3 \\
\hline
\end{tabular}


Table 2. Demographic characteristics of patients with and without metastases

\begin{tabular}{|c|c|c|c|c|c|c|c|c|c|c|c|c|}
\hline \multirow[t]{2}{*}{ Features } & \multicolumn{2}{|c|}{ Lung Metastasis } & \multirow{2}{*}{$\begin{array}{l}P \\
\text { value }\end{array}$} & \multicolumn{2}{|c|}{ Liver Metastasis } & \multirow{2}{*}{$\begin{array}{l}P \\
\text { value }\end{array}$} & \multicolumn{2}{|c|}{ Bone Metastasis } & \multirow{2}{*}{$\begin{array}{l}P \\
\text { value }\end{array}$} & \multicolumn{2}{|c|}{ Brain Metastasis } & \multirow{2}{*}{$\begin{array}{l}P \\
\text { value }\end{array}$} \\
\hline & No & Yes & & No & Yes & & No & Yes & & No & Yes & \\
\hline Gender & & & 0.076 & & & 0.021 & & & 0.081 & & & 0.294 \\
\hline Male & 5034 & 49 & & 5073 & 10 & & 5057 & 26 & & 5079 & 4 & \\
\hline Female & 1092 & 18 & & 1103 & 7 & & 1099 & 11 & & 1108 & 2 & \\
\hline Age & & & 0.462 & & & 0.149 & & & 0.248 & & & 0.426 \\
\hline$\leq 59$ & 3274 & 39 & & 3307 & 6 & & 3297 & 16 & & 3311 & 2 & \\
\hline$>59$ & 2852 & 28 & & 2869 & 11 & & 2859 & 21 & & 2876 & 4 & \\
\hline Race & & & 0.143 & & & 0.000 & & & 0.000 & & & 0.086 \\
\hline Caucasian & 5393 & 54 & & 5436 & 11 & & 5424 & 23 & & 5443 & 4 & \\
\hline Asian & 218 & 3 & & 221 & 0 & & 219 & 2 & & 221 & 0 & \\
\hline African American & 515 & 10 & & 519 & 6 & & 513 & 12 & & 523 & 2 & \\
\hline Grade & & & 0.033 & & & 0.184 & & & 0.360 & & & 0.783 \\
\hline 1 & 272 & 0 & & 272 & 0 & & 272 & 0 & & 272 & 0 & \\
\hline 2 & 2476 & 36 & & 2508 & 4 & & 2498 & 14 & & 2510 & 2 & \\
\hline 3 & 3378 & 31 & & 3396 & 13 & & 3386 & 23 & & 3405 & 4 & \\
\hline $\mathrm{T}$ classification & & & 0.000 & & & 0.000 & & & 0.000 & & & 0.007 \\
\hline $\mathrm{T} 1$ & 1826 & 9 & & 1833 & 2 & & 1829 & 6 & & 1835 & 0 & \\
\hline $\mathrm{T} 2$ & 2470 & 14 & & 2480 & 4 & & 2470 & 14 & & 2481 & 3 & \\
\hline T3 & 1006 & 17 & & 1021 & 2 & & 1019 & 4 & & 1023 & 0 & \\
\hline T4a & 548 & 18 & & 558 & 8 & & 557 & 9 & & 563 & 3 & \\
\hline $\mathrm{T} 4 \mathrm{~b}$ & 276 & 9 & & 284 & 1 & & 281 & 4 & & 285 & 0 & \\
\hline $\mathbf{N}$ classification & & & 0.000 & & & 0.000 & & & 0.000 & & & 0.527 \\
\hline No & 1256 & 3 & & 1258 & 1 & & 1253 & 6 & & 1257 & 2 & \\
\hline N1 & 1288 & 8 & & 1293 & 3 & & 1292 & 4 & & 1295 & 1 & \\
\hline N2a & 716 & 3 & & 719 & 0 & & 718 & 1 & & 719 & 0 & \\
\hline $\mathrm{N} 2 \mathrm{~b}$ & 2069 & 18 & & 2083 & 4 & & 2078 & 9 & & 2086 & 1 & \\
\hline $\mathrm{N} 2 \mathrm{c}$ & 529 & 26 & & 549 & 6 & & 542 & 13 & & 554 & 1 & \\
\hline N3 & 268 & 9 & & 274 & 3 & & 273 & 4 & & 276 & 1 & \\
\hline Tumor location & & & 0.937 & & & 0.130 & & & 0.033 & & & 0.712 \\
\hline Tonsillar fossa & 763 & 7 & & 769 & 1 & & 767 & 3 & & 769 & 1 & \\
\hline Tonsillar pillar & 376 & 4 & & 378 & 2 & & 379 & 1 & & 379 & 1 & \\
\hline Overlapping lesion of tonsil & 60 & 1 & & 60 & 1 & & 59 & 2 & & 61 & 0 & \\
\hline Tonsil, NOS & 4927 & 55 & & 4969 & 13 & & 4951 & 31 & & 4978 & 4 & \\
\hline
\end{tabular}

Abbreviations: NOS: not otherwise specified.

\section{Metastasis pattern}

At the time of diagnosis, there were 17 patients with liver metastasis, 67 patients with lung metastasis, 37 patients with bone metastasis and 6 patients with brain metastasis.

As shown in Table 2, tumor grade was found to be significantly correlated with lung metastasis and poorly/undifferentiated differentiation was an independent prognostic parameter for higher prevalence of lung metastasis $(p=0.033)$. What's more, we observed that $\mathrm{T}$ classification was also an independent parameter for metastatic diseases. A higher $\mathrm{T}$ classification was associated with higher prevalence of lung, bone, liver and brain metastasis ( $p=0.000, p=0.000, p=0.000$ and $p=0.007$, respectively). The same results were found in $\mathrm{N}$ classification in lung, bone, and liver metastasis $(p=0.000, p=0.000$, and $p=0.000$, respectively). In addition, liver and bone metastases were associated with African American ( $p=0.000$ and $p=0.000$, respectively).

\section{Survival}

The overall mean follow-up of all patients in the cohort was 21.0 months (range, 0-59 months). In the univariate analysis, age, gender, race, grade, primary site, $\mathrm{T}$ category, $\mathrm{N}$ category, distant metastases and surgery therapy were significantly associated with OS and CSS $(P<0.05)$.

Gender, age, race, grade, primary site, $\mathrm{T}$ classification, $\mathrm{N}$ classification, history of surgery and distant metastases were selected in the multivariate model. Age, race, grade, primary site, T classification, $\mathrm{N}$ classification, surgery therapy and distant metastases were all independent prognostic factors in the multivariable analysis for CSS (Table 3). Elderly black patients with higher $\mathrm{T}$ or $\mathrm{N}$ classification, multiple sites of metastases and no surgical therapy to primary tumor were more likely to reduce life expectancy.

As shown in Figure 2, 5-year CSS are 93.6\% and $84.5 \%$ for localized and regional TSCC patients, respectively, which are much higher than metastatic TSCC patients (62.6\%). The same results were found in OS.

\section{Discussion}

In this study, 6193 patients with TSCC were evaluated and $86(0.13 \%)$ patients had synchronous distant metastases at diagnosis. In the present series, 
the niches of distant metastasis were predominantly located in the lungs, bones, liver and brain, in accordance with the literature [5]. We observed some interesting relationships between the clinicopathological characteristics and distant metastases patterns. For instance, liver and bone metastases were associated with African American. Nabil et al. found that TSCC in white men is likely human papillomavirus (HPV) driven, and Frederic et al. found that HPV-negativity are factors associated with the development of distant metastases, which could partly explain the observed ethnic-based differences $[6,7]$. However, absence of information about HPV and/or p16 status of the patients in the current analysis prevented us to adjust our analyses for these important factors. What's more, advanced $\mathrm{T}$ classifications increased the risk of distant metastases and advanced regional disease (N2 or N3 disease) are found in patients with M1 disease, which were consistent with many other studies [7-10].

A number of variables influencing the prognosis of TSCC have been described previously (Table 3). In the present study, eight clinicopathological factors were found to be associated with patient OS by univariate analysis, including age, race, grade, primary site, $\mathrm{T}$ classification, $\mathrm{N}$ classification, distant metastases and surgery therapies. Based on the present study, Caucasian was associated with a better prognosis than Asian and African American. In terms of age, several reports have shown that patients' age is one of the prognostic factors in oropharyngeal carcinoma including TSCC $[11,12]$. The differential protective effect of marriage based on HPV infection, which correlated with favorable prognosis, was more frequently observed in younger Caucasian patients than in the elderly [13]; therefore, old aged African American could be secondary surrogates of poor tumor biology which is unrelated to HPV infection. Unfortunately, because the HPV and/or p16 status of patients in the present study was unknown, this hypothesis could not be tested. Regarding that many recent studies for altering therapy based on HPV status are in progress, the lack of details of HPV status in this study has significant limitations [14].

Table 3. Multivariable logistic regression for OS and CSS of TSCC in the SEER cohort

\begin{tabular}{|c|c|c|c|c|c|c|c|c|}
\hline \multirow[t]{2}{*}{ Prognostic factor } & \multicolumn{4}{|c|}{ Overall survival } & \multicolumn{4}{|c|}{ Cancer-specific survival } \\
\hline & $P$ value & HR & Lower CI & Higher CI & $P$ value & HR & Lower CI & Higher CI \\
\hline Age & 0.000 & 1.843 & 1.625 & 2.090 & 0.000 & 1.738 & 1.477 & 2.046 \\
\hline Gender & 0.344 & & & & 0.251 & & & \\
\hline Male & & 1 (refe & & & & 1 (refer & & \\
\hline Female & & 1.054 & 0.904 & 1.229 & & 1.094 & 0.893 & 1.341 \\
\hline Race & 0.000 & & & & 0.000 & & & \\
\hline Caucasian & & 1 (refe & & & & 1 (refer & & \\
\hline Asian & & 1.231 & 0.894 & 1.694 & & 1.256 & 0.847 & 1.860 \\
\hline African American & & 1.694 & 1.432 & 2.003 & & 1.663 & 1.328 & 2.082 \\
\hline Grade & 0.000 & & & & 0.000 & & & \\
\hline 1 & & 1 (refe & & & & 1 (refer & & \\
\hline 2 & & 0.789 & 0.610 & 1.020 & & 0.649 & 0.454 & 0.927 \\
\hline 3 & & 0.575 & 0.443 & 0.746 & & 0.439 & 0.306 & 0.629 \\
\hline T classification & 0.000 & & & & 0.000 & & & \\
\hline $\mathrm{T} 1$ & & 1 (refe & & & & 1 (refer & & \\
\hline $\mathrm{T} 2$ & & 1.172 & 0.971 & 1.415 & & 1.192 & 0.914 & 1.555 \\
\hline T3 & & 1.753 & 1.422 & 2.161 & & 1.860 & 1.397 & 2.476 \\
\hline T4a & & 2.591 & 2.084 & 3.220 & & 3.032 & 2.257 & 4.072 \\
\hline $\mathrm{T} 4 \mathrm{~b}$ & & 3.181 & 2.471 & 4.094 & & 3.563 & 2.557 & 4.964 \\
\hline $\mathbf{N}$ classification & 0.285 & & & & 0.000 & & & \\
\hline No & & 1 (refe & & & & 1 (refer & & \\
\hline N1 & & 0.843 & 0.696 & 1.021 & & 1.228 & 0.926 & 1.628 \\
\hline $\mathrm{N} 2 \mathrm{a}$ & & 0.684 & 0.519 & 0.901 & & 0.838 & 0.562 & 1.248 \\
\hline $\mathrm{N} 2 \mathrm{~b}$ & & 0.828 & 0.697 & 0.984 & & 1.167 & 0.903 & 1.508 \\
\hline $\mathrm{N} 2 \mathrm{C}$ & & 1.121 & 0.907 & 1.386 & & 1.613 & 1.208 & 2.154 \\
\hline N3 & & 1.229 & 0.935 & 1.615 & & 2.004 & 1.421 & 2.826 \\
\hline Tumor location & 0.000 & & & & 0.003 & & & \\
\hline Tonsillar fossa & & 1 (refe & & & & 1 (refer & & \\
\hline Tonsillar pillar & & 1.145 & 0.889 & 1.474 & & 1.100 & 0.784 & 1.544 \\
\hline Overlapping lesion of tonsil & & 0.964 & 0.568 & 1.636 & & 0.823 & 0.414 & 1.636 \\
\hline Tonsil, NOS & & 0.819 & 0.695 & 0.965 & & 0.790 & 0.635 & 0.982 \\
\hline Surgery therapy & 0.000 & 1.890 & 1.636 & 2.183 & 0.000 & 2.276 & 1.859 & 2.788 \\
\hline Distant metastases & 0.000 & & & & 0.000 & & & \\
\hline No & & 1 (refe & & & & 1 (refer & & \\
\hline Single & & 3.790 & 2.821 & 5.093 & & 4.972 & 3.586 & 6.893 \\
\hline Multiple & & 8.192 & 4.844 & 13.854 & & 12.145 & 6.799 & 21.695 \\
\hline
\end{tabular}


A

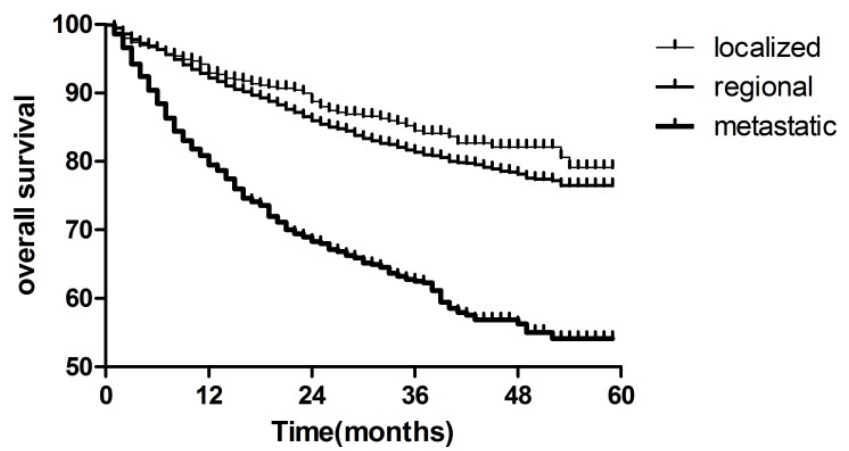

B

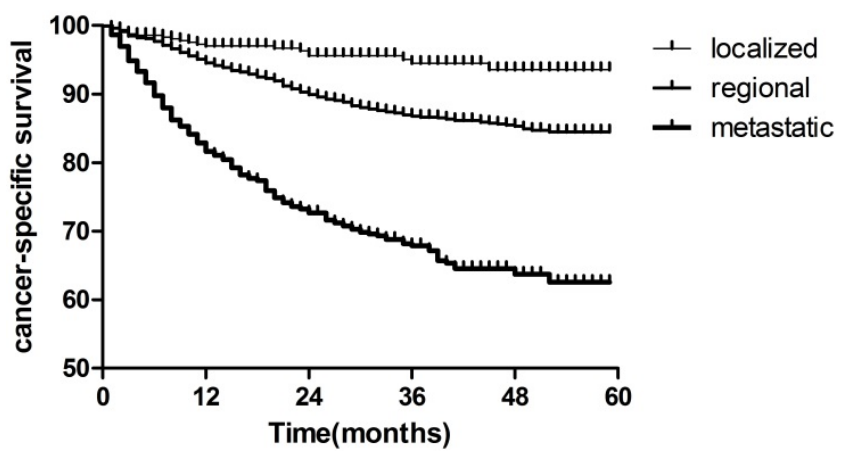

Figure 2. Kaplan-Meier analysis of overall survival and cancer-specific survival in localized, regional and metastatic tonsil squamous cell carcinomas patients. A, overall survival in localized, regional and metastatic tonsil squamous cell carcinomas patients $(P<0.05)$. B, cancer-specific survival in localized, regional and metastatic tonsil squamous cell carcinomas patients $(P<0.05)$

Furthermore, early diagnosis and treatment are particularly important; especially the incidence of TSCC has increased in past 3 decades $[2,3,15,16]$. We observed that 5 -year CSS are $93.6 \%$ and $84.5 \%$ for localized and regional TSCC patients, respectively, which are much higher than metastatic TSCC patients(62.6\%). we observed the same pattern of associations for OS (Figure 2).

This is the first population-based analysis assessing prevalence proportion and prognostic factors of distant metastases of TSCC patients. Some limitations of our study should be acknowledged. First of all, the SEER database only provides information about four sites of metastases at diagnosis: bone, brain, lung, and liver. We don't have information of metastasis to other sites, which may influence the prognostic assessment of the metastases group. Second, the lack of data on additional predictors of OS such as HPV and/or p16 status, performance status, comorbidities, chemotherapy and/or postoperative radiotherapy, positive surgical margins at final pathology prevented us to adjust our analyses for these important factors.

\section{Conclusion}

Lung was the most frequent lesion of synchronous distant metastases and liver and bone metastases were associated with African American. Higher $\mathrm{T}$ and $\mathrm{N}$ classification were independent prognostic parameters for higher prevalence of lung, bone, liver and brain metastasis. Worse prognosis was associated with older age, African Americans, lower grade, higher $\mathrm{T}$ and $\mathrm{N}$ classification, no surgery therapy and more metastatic sites.

\section{Acknowledgements}

We acknowledge the support of the Department of Radiation Oncology, Fudan University Shanghai Cancer Center. The views expressed in this publication are those of the authors.

\section{Ethical Approval and Informed Consent}

All procedures performed in studies involving human participants were in accordance with the ethical standards of Fudan University Shanghai Cancer Center Ethics committee and with the 1964 Helsinki declaration and its later amendments or comparable ethical standards. The experimental protocols were also approved by Fudan University Shanghai Cancer Center Ethics committee. Written informed consent was obtained from all individual participants included in the study.

\section{Availability of data and materials}

The datasets used and/or analysed during the current study are available from the corresponding author on reasonable request.

\section{Funding}

The study was funded by the National Key Technologies Research and Development Program on Prevention and Control of Chronic Noncommunicable Diseases (Grant No. 2018YFC1313204).

\section{Author Contributions}

Yujiao $\mathrm{Li}$ and Chaosu $\mathrm{Hu}$ have made substantial contributions to all of the following: (1) the conception and design of the study, or acquisition of data, or analysis and interpretation of data, (2) drafting the article or revising it critically for important intellectual content, (3) final approval of the version to be submitted.

\section{Competing Interests}

The authors have declared that no competing interest exists. 


\section{References}

[1] Ryerson AB, Peters ES, Coughlin SS, et al. Burden of potentially human papillomavirus-associated cancers of the oropharynx and oral cavity in the US, 1998-2003. CANCER-AM CANCER SOC. 2008,113(10 Suppl) :2901-2909.

[2] Schantz SP, Yu GP. Head and neck cancer incidence trends in young Americans, 1973-1997, with a special analysis for tongue cancer. Arch Otolaryngol Head Neck Surg. 2002,128(3) :268-274.

[3] Shiboski $\mathrm{CH}$, Schmidt $\mathrm{BL}$, Jordan RCK. Tongue and tonsil carcinoma: Increasing Trends in the U.S. Population Ages 20-44 Years. CANCER-AM CANCER SOC. 2005,103(9):1843-1849.

[4] Forastiere A, Goepfert H, Goffinet D, et al. NCCN practice guidelines for head and neck cancer. National Comprehensive Cancer Network. Oncology (Williston Park). 1998,12(7A):39-147.

[5] Sacks R, Law JY, Zhu H, et al. Unique patterns of distant metastases in HPV-Positive head and neck cancer. Oncology. 2020,98(3):179-185.

[6] Saba NF, Goodman M, Ward K, et al. Gender and ethnic disparities in incidence and survival of squamous cell carcinoma of the oral tongue, base of tongue, and tonsils: A surveillance, epidemiology and end results Program-Based analysis. Oncology. 2011,81(1):12-20.

[7] Duprez F, Berwouts D, De Neve W, et al. Distant metastases in head and neck cancer. Head Neck. 2017,39(9):1733-1743.

[8] Weller MA, Ward MC, Berriochoa C, et al. Predictors of distant metastasis in human papillomavirus-associated oropharyngeal cancer. Head Neck. 2017,39(5): 940-946.

[9] Ferlito A, Shaha AR, Silver CE, et al. Incidence and sites of distant metastases from head and neck cancer. O.R.L. Journal for oto-rhino-laryngology and its related specialties. 2001,63(4):202-207.

[10] Uhliarová B, Švec M. Incidence and risk factors of distant metastases of head and neck carcinoma. Klinicka Onkologie. 2019,32(4):294-299.

[11] Song S, Wu H, Lee CG, et al. Chemoradiotherapy versus surgery followed by postoperative radiotherapy in tonsil cancer: Korean Radiation Oncology Group (KROG) study. BMC CANCER. 2017,17(1).

[12] Koo TR, Wu H, Hah JH, et al. Definitive Radiotherapy versus Postoperative Radiotherapy for Tonsil Cancer. CANCER RES TREAT. 2012,44(4):227-234.

[13] Westra WH. The changing face of head and neck cancer in the 21st century: The impact of HPV on the epidemiology and pathology of oral cancer. Head Neck Pathol. 2009,3(1):78-81.

[14] Vokes EE, Agrawal N, Seiwert TY. HPV-Associated head and neck cancer. J Natl Cancer Inst. 2015,107(12): v344.

[15] Reddy VM, Cundall-Curry D, Bridger M. Trends in the incidence rates of tonsil and base of tongue cancer in England, 1985-2006. The Annals of The Royal College of Surgeons of England. 2010,92(8):655-659.

[16] Olaleye O, Moorthy R, Lyne O, et al. A 20-year retrospective study of tonsil cancer incidence and survival trends in South East England: 1987-2006. CLIN OTOLARYNGOL. 2011,36(4):325-335 